\title{
Analysis of Avocado Leaf, Casmir Leaf and Morenga Leaf for the Detection of Concentration of Chlorophyll a and Chlorophyll b
}

\author{
Desissa Yadata \\ Mizan Tepi, t office 121, Ethiopia \\ *Corresponding Author: desissayad@yahoo.com
}

Copyright $@ 2014$ Horizon Research Publishing All rights reserved.

\begin{abstract}
hotosynthesis can be influenced directly by the concentration of chlorophyll and hence detection of such important pigment is the central point of the work under study. The objective of the work is determination of the concentration of leaf pigments particularly chlorophyll a and chlorophyll b. UV-Visible spectrophotometer is used to determine the absorbance of leaf samples obtained from three different plant species Shiferaw, Casmir and avocado; three replicate samples has been considered in each plant species. The samples collected in each species were preserved at $-20^{\circ} \mathrm{C}$ and dark area. The sample preserved under such a condition is weighed i.e.; $2 \mathrm{~g}$ of each fresh leaf sample considered and crashed in $80 \%$ acetone and the extract was filtered with what man filter paper №42. After the dilution of the extract the absorbance was determined for chlorophyll a and chlorophyll b at $663 \mathrm{~nm}$ and $649 \mathrm{~nm}$ respectively. From the absorbance data; the corresponding concentration determined. According to the calculation concentration of chl a in shiferaw is $0.136 \mathrm{mg} / \mathrm{Kg}$ in Casmir $0.229 \mathrm{mg} / \mathrm{Kg}$ and $0.1144 \mathrm{mg} / \mathrm{Kg}$ in avocado. The concentration of chlorophyll $\mathrm{b}$ in avocado is $0.108 \mathrm{mg} / \mathrm{kg}$ in shiferaw, $0.214 \mathrm{mg} / \mathrm{Kg}$ and $0.102 \mathrm{mg} / \mathrm{Kg}$ in Casmir leaf sample. The concentration of chlorophyll a is greater than chlorophyll $b$ which coincides with the fact that the abundance of chlorophyll $\mathrm{a}$ is greater than the chlorophyll $\mathrm{b}$ in most land trees.
\end{abstract}

Keywords Vocado, Casmir, Chlorophyll, Leaf Pigments, Photosynthesis, Shiferwa

\section{Introduction}

The most abundant plant pigments are chlorophyll a and $b$; their concentration can be varied because of the cells physiological state and composition. In most land plants there are typically two types of Chlorophyll (Chl) molecules, namely, chlorophyll a, $\mathrm{C}_{55} \mathrm{H}_{72} \mathrm{O}_{5} \mathrm{~N}_{4} \mathrm{Mg}$ and chlorophyll $\mathbf{b}$,
$\mathrm{C}_{55} \mathrm{H}_{70} \mathrm{O}_{6} \mathrm{~N}_{4} \mathrm{Mg}$. Both of these pigments absorb photons of light in the blue and red spectral regions, but the specific wavelengths of light they absorb are different. The maximum photons absorbance for chlorophyll a is at $663 \mathrm{~nm}$ and that of chlorophyll b is at $649 \mathrm{~nm}$. Because the absorption spectra of these two Chlorophyll molecules overlap, simultaneous equation used to solve for the amount of both pigments. The equation for this has been worked out and is known as Arnon's equation and now a day modified to be Porras equation. Over the past seventy years, the extinction coefficients for the chlorophyll pigments have been refined and are now considered exceptionally accurate [1].

The kinds of plant species selected for the current study are Moringa (Shiferaw), Casmir and Avocado. The chlorophylls of these plants are therefore one of the most critical compositions to be concerned since it maintains natural equilibrium of ecological events in animal's kingdom and plants kingdom. In addition chlorophyll has a trend of capturing the coming sun light for the purpose of photosynthesis. These processes minimize the concentration of $\mathrm{CO}_{2}$ affecting the total heat of the atmosphere by releasing useful $\mathrm{O}_{2}$ as by product [2].

The objective of the study is determination of the concentration of chlorophyll a and chlorophyll $b$ and compares the concentration of each pigment with one another.

The method is focused on the study of plants characteristics on the basis of their leaf composition using Uv-visible spectroscopy and the feedback of the work become critical in controlling and advancing the relationship between chlorophyll and environmental significance.

\section{Materials and Methods}

\subsection{Reagents, Apparatuses and Instrumentation}

The common reagents used in the work were $80 \%$ acetone 
solution, distilled water and ethanol.

The common apparatuses are mortar and Pestle, Cuvette, UV-visible spectrophotometer (single beam), $100 \mathrm{mLV}$ olumetric flasks what man filter paper (NO42) and Filtering funnel.

\subsection{Sampling and Sample Collection}

The sample was collected from Tepi town located at about $611 \mathrm{Km}$ from Addis Ababa and the samples are Morenga (Shiferaw), Avocado and Casmir leaf. In each species three replicate and hence total of nine replicate samples have been collected randomly from the site. The samples were preserved under $-20^{\circ} \mathrm{C}$ and at dark area to avoid direct exposure to radiation [3].

\subsection{Sample Preparation}

Plants leaf cut into pieces(to discard veins) and $2 \mathrm{~g}$ of each plant leaf was weighed and crashed in $10 \mathrm{~mL}$ of $80 \%$ acetone solution (prepared by mixing $80 \mathrm{~mL}$ of acetone into $20 \mathrm{~mL}$ of distilled water) using mortar and pestle. The extract was filtered with what man filter paper No 42 to separate from residue material. UV-Spectrophotometer was turned on before 15 minutes to carry out analysis. For the purpose of calibration, part of $80 \%$ acetone was used as blank solution and its absorbance was determined at 663nm (maximum wave length of chl a) and the possible lowest absorbance reading of the method was recorded. Sample solution of each plant leaf diluted by the ratio of 1:10 (sample: $80 \%$ acetone) was prepared and analyzed for chl $\mathbf{a}$ and the corresponding absorbance of the samples was recorded at specified wave length. The spectrophotometer was recalibrated at $649 \mathrm{~nm}$ (maximum wave length of chl b) with blank solution prepared from $80 \%$ acetone solution and its absorbance reading nearly become 0 . The sample extract solution was diluted in the ratio of 1:10 (sample: solvent) and some of it was added into cuvette to measure the absorbance at $649 \mathrm{~nm}$ for chlorophyll b [4].

\section{Results and Discussion}

\subsection{Absorbance Measurement}

The absorbance is the response of radiation that is absorbed in the medium or sample and hence it corresponds to the amount of analyte present in the sample and related by the Beer Lambert equation $\mathrm{A}=2-\log \mathrm{T} \%$ or $\mathrm{A}=\varepsilon l c$, where $\mathrm{A}, \mathrm{T} \%, \varepsilon, l \& c$. The maximum wave lengths at which chlorophyll a analyzed was $663 \mathrm{~nm}$ and that of chl b was $649 \mathrm{~nm}$. The absorbance of solution was determined in the order of blank and then sample. The collected absorbance was used to determine the corresponding concentration of sample as it is described in table 1 .

Table 1. Sample absorbance

\begin{tabular}{|c|c|c|c|}
\hline Wave length & Morenga(shiferaw) & Casmir & Avocado \\
\hline \multirow{3}{*}{$663 \mathrm{~nm}$} & 0.690 & 0.554 & 0.291 \\
\cline { 2 - 4 } & 0.680 & 0.563 & 0.293 \\
\cline { 2 - 4 } & 0.600 & 0.576 & 0.294 \\
\hline \multirow{3}{*}{$649 \mathrm{~nm}$} & 0.429 & 0.405 & 0.246 \\
\cline { 2 - 4 } & 0.431 & 0.408 & 0.251 \\
\cline { 2 - 4 } & 0.438 & 0.409 & 0.256 \\
\hline
\end{tabular}

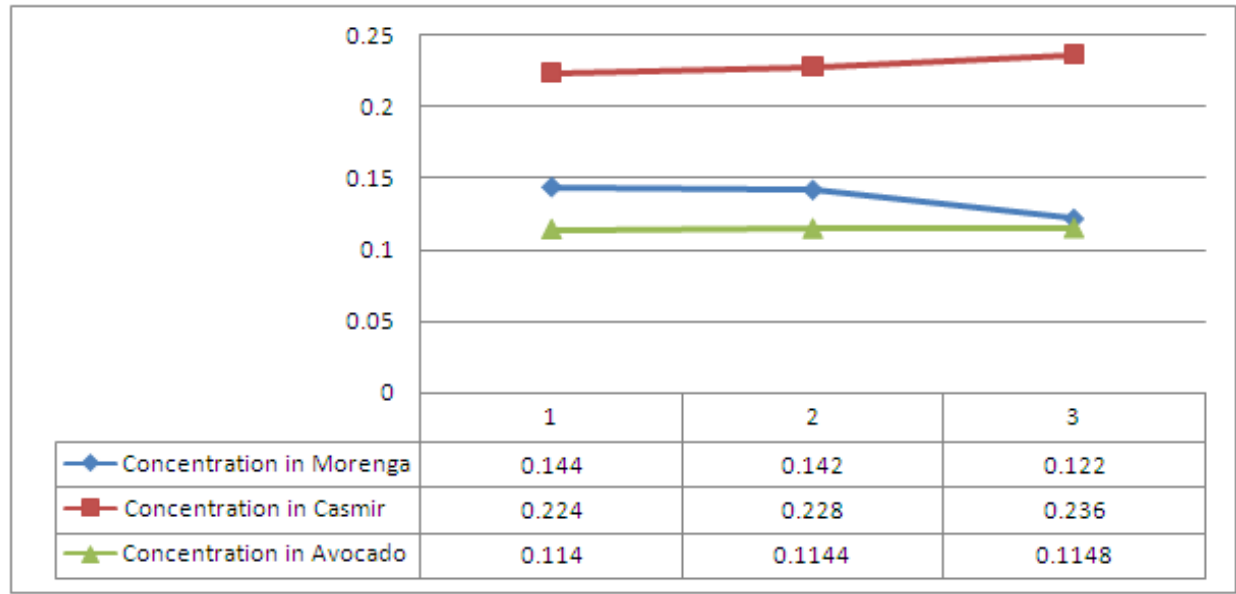

Figure 1. The concentration of chlorophyll a in Morenga, Casmir and Avocado leaf sample 


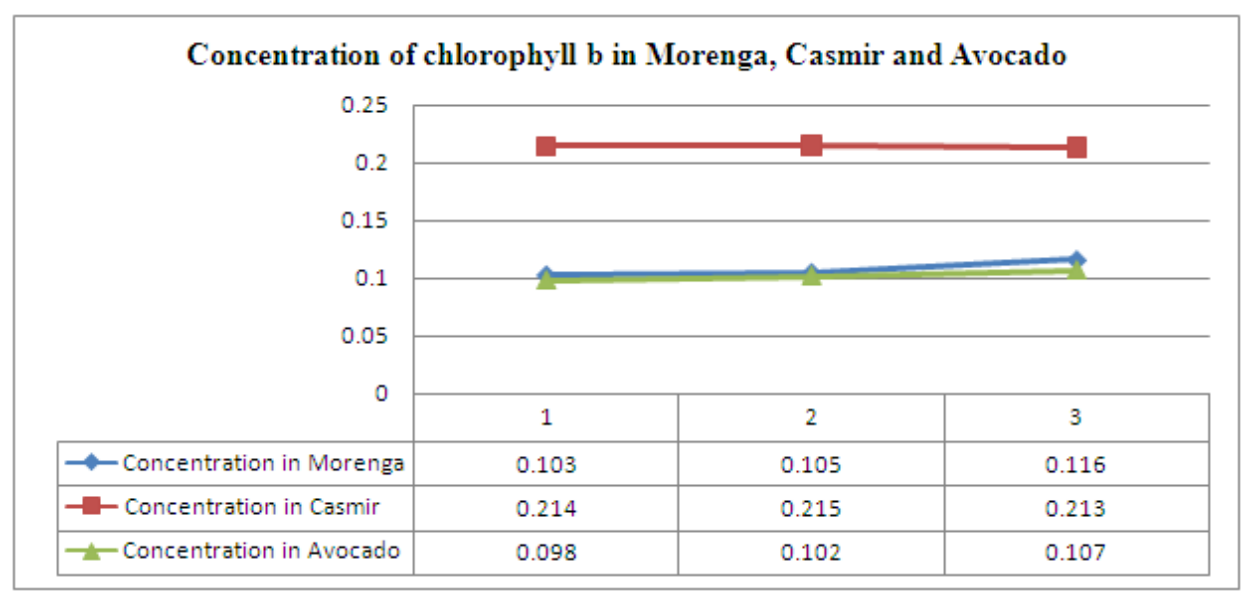

Figure 2. The concentration of chlorophyll $b$ in Morenga, Casmir and Avocado leaf sample

From table1 the absorbance reading are shown and in all the cases it is less than 0.7 and greater than 0.1 . The absorbance in case of Morenga at $663 \mathrm{~nm}$ and $649 \mathrm{~nm}$ is higher than any of the plants studied [6].

Another fact that can be explained from the table is the relationship between the absorbance at $663 \mathrm{~nm}$ and $649 \mathrm{~nm}$. At $663 \mathrm{~nm}$ the absorbance become higher in all the samples than at $649 \mathrm{~nm}$, in other words chlorophyll a absorbed at smaller energy than chlorophyll $\mathbf{b}$ which may be explained in terms of arrangement of atoms in the molecules[7].

\subsection{Concentration of Chlorophyll in Leaf Sample}

The concentration of pigments was determined from the absorbance reading using the Beer-Lambert equation $\mathrm{A}=\alpha \mathrm{lc}$ relationship in coordination with Lichtenthaler and Welburn who reported accurate Beer-Lambert absorption coefficients for the major pigments of photosynthesis, allowing their concentrations to be easily determined from absorbance reading displayed by spectrophotometer[8].

- $\quad[$ Chlorophyll a $]\left(\mathrm{mgL}^{-1}\right)=12.21(\mathrm{~A} 663)-2.81$ (A649)

- $\quad$ Chlorophyll b] $\left(\mathrm{mgL}^{-1}\right)=20.13(\mathrm{~A} 649)-5.03$ (A663)

A663 and A649 are absorbance of chlorophyll "a" at $663 \mathrm{~nm}$ and chlorophyll "b" at $649 \mathrm{~nm}$ respectively. The concentration obtained by this method was multiplied by the reciprocal of dilution ratio i.e. by 10 since the extract was diluted by 1:10 for Morenga using the formula $C_{1} V_{1}=$

$\mathrm{C}_{2} \mathrm{~V}_{2}$ where $\mathrm{C}_{1} \mathrm{~V}_{1}$ is amount before dilution and $\mathrm{C}_{2} \mathrm{~V}_{2}$ is amount after dilution. The actual concentration of the extract was not detected in concentrated solution sample. Hence dilution become way of handling the problem and it was carried out using the formula $C_{1} V_{1}=C_{2} V_{2}$. Where $\left(C_{1}\right)$ is more concentrated and corresponding volume is $\mathrm{V}_{1}$; whereas $\mathrm{C}_{2}$ is less concentrated and corresponding volume is $\mathrm{V}_{2}$. Therefore for the calculation of concentration in original leaf extract; the appropriate formula become $\mathrm{C}_{1}=\mathrm{C} 2 \mathrm{~V} 2 / \mathrm{V} 1$ $\mathrm{V} 2$ is $10 \mathrm{~mL}$ which is the reciprocal of dilution factor. Finally the concentration, $C_{1}$ was multiplied by 0.002 ,
$\left(\frac{C 1 \times 0.002}{K g}\right)$ to express in terms of total weight of the leaf used for obtaining the extract and the results described in table 2.

Unlike extract of Morenga, Casmir and avocado was multiplied by the dilution factor of 20 since the extract was diluted in the proportion of 1:20. The results explained in table 2

$$
\mathrm{C}_{1}=\mathrm{C} 2 \mathrm{~V} 2 / \mathrm{V} 1, \mathrm{~V} 2 \text { is } 20 .
$$

Table 2. Sample Concentration $(\mathrm{mg} / \mathrm{Kg})$, of the three plant species

\begin{tabular}{|c|c|c|c|}
\hline $\begin{array}{c}\text { Wave } \\
\text { length }\end{array}$ & Morenga & Casmir & Avocado \\
\hline $663 \mathrm{~nm}$ & $0.136 \pm 0.012$ & $0.229 \pm 0.006$ & $0.1144 \pm 0.0004$ \\
\hline $649 \mathrm{~nm}$ & $0.108 \pm 0.007$ & $0.214 \pm 0.001$ & $0.102 \pm 0.0045$ \\
\hline
\end{tabular}

From table2 the concentration of chlorophyll a is higher than that of chlorophyll $b$ in all sample studied.

\section{Conclusions}

The maximum absorbance for chlorophyll $\mathbf{a}$ and chlorophyll b were determined at $663 \mathrm{~nm}$ and $649 \mathrm{~nm}$ respectively. The concentration of pigments determined simultaneously using Porra's 2002 and the results obtained from three different leaf samples showed that, concentration of chlorophyll $a$ is higher than that of chlorophyll $b$ in each sample and concentration of pigments varied among the leaf samples that is the content of chlorophyll a and chlorophyll b in Morenga is lower than Casmir and higher than in avocado sample. More over concentration of each leaf sample was related directly to absorbance.

\section{REFERENCES}


[1] U. C. malavasi and M. M. malavasi (1999) Leaf characteristics and chlorophyll concentration of Schyzolobium parahybum and Hymenia stilbocarpa seedlings grown in different light regimes Tree Physiology vol. 21 Brazil

[2] Melchior, (2007) Spectrophotometric Determination of Photosynthetic Pigment Concentrations.

[3] Lichtenthaler, HK and AR Wellborn (1983) Determinations of total carotenoids and chlorophylls a and b of leaf extracts in different solvents. Biochemical Society Transactions V.11: pp.591 - 592 .

[4] Porra, RJ (2003), the chequered history of the development and use of simultaneous equations for the accurate determination of chlorophylls $\mathrm{a}$ and $\mathrm{b}$.

[5] Anatoly A. Gitelson1, (2003) Relationships between leaf chlorophyll content and spectral reflectance and algorithms for non-destructive chlorophyll assessment in higher plant leaves. Plant Physiol. V.160, pp. 271 - 282, Russia

[6] DOS SANTOS ${ }^{1}$, A.C.A., and CALIJURI 2 (2003) Comparison of three methods for Chlorophyll determination:

[7] Mark Lefsrud ${ }^{1}$ (2008) Dry Matter Content and Stability of Carotenoids in Kale and Spinach

[8] Dean A. Kopsell, 2005, Carotenoid and chlorophyll pigments in sweet Basil grown in the field and green house 40(5), pp1230-1233 